\title{
Implementation of the Kobe City Recovery Plan*
}

\section{Yuichi HONJO}

\begin{abstract}
The city of Kobe formulated the ten-year Kobe Recovery Plan immediately after the occurrence of the Great Hansin-Awaji Earthquake in 1995. The author, a Kobe City official describes the lessons learned in promoting the Kobe City Recovery Plan. Specifically, this article uses the results of the Comprehensive Recovery Assessments in 1999 and 2003, before the fifth and tenth anniversaries respectively, to suggest strategies for promoting a recovery plan, and to convey the importance of adopting "self-governance and community solidarity" as values in the recovery process as well as expanding "social capital" to support those values.
\end{abstract}

KEYWORDS: The Great Hansin-Awaji Earthquake, PDCA cycle, outcome indices for policy assessments, self-governance and community solidarity, social capital

\section{INTRODUCTION}

It has been 16 years since the Great Hanshin-Awaji Earthquake (referred to hereinafter throughout this paper as the Hanshin Earthquake). The Hanshin Earthquake struck Japan at 5:46 a.m. on January 17, 1995. This was the first major earthquake to occur in very close proximity to a large Japanese city in the post-war era, and severe seismic activity was recorded in densely populated Awaji, Kobe, and Hanshin urban areas. The magnitude of the earthquake, which describes the extent of destruction at the focal point, was 7.3.

The damage caused by the Hanshin Earthquake was as follows: the death and missing toll stands at 6,437 persons, and total monetary loss for Hyogo and the surrounding areas stands at around 10 trillion yen. In Kobe, the downtown areas on the south side of the Rokko Mountains were the most severely affected with the number of deaths totaling more than 4,500. More than 80,000 houses were lost, and many vital parts of the urban infrastructure that Kobe had been building up such as the port, expressways, bridges, railway facilities, and lifelines were severely damaged. In addition to that, industrial structures were heavily damaged to the tune of about 7 trillion yen.

In order to swiftly formulate measures towards recovery in Kobe, on January 26, 1995, just 9 days after the earthquake, the mayor announced his basic vision for recovery. The basic principle as indicated in "The New Kobe City Basis Concept" was that Kobe "shall build a disaster-safe model city where citizens can live and work in a safe and secure manner through the swift recovery of the urban infrastructure, civic life and urban development" and that Kobe "shall create a new Kobe that will become a civic-minded creative city interacting with the world." Based on this basic principle, the Kobe City Recovery Plan, which covered a 10-year period, was formulated in June 1995.

The formulated plan will be meaningful only when the visions described in the plan are actualized. Therefore, to proceed steadily with recovery in the affected areas, it is important to continually evaluate the recovery progress and to review and revise the measures in order to make the plan more feasible. Based on this management concept, Kobe assessed the recovery progress and reviewed and then revised

The author is the Director of the Kobe City Planning and Coordination Bureau and Executive Director of the Kobe Institute of Urban Research.

\footnotetext{
* This is a modified version of an article written by the author in the report, Honjo, Y. ed. "Comprehensive Strategy for
} Recovery from the Great Hanshin-Awaji Earthquake,” Kobe Institute of Urban Research, March 2010. 
the plan based on the results.

In this paper, I describe the lessons I learned through my experiences as a city official promoting the Kobe City Recovery Plan. Specifically, I want to use the results of the Comprehensive Recovery Assessments conducted in 1999, before the fifth anniversary of the quake, and 2003, before the tenth anniversary, to suggest strategies for promoting a recovery plan, and to convey the importance of adopting "self-governance and community solidarity" as values in the recovery process and expanding "social capital" to support those values.

\section{MANAGEMENT OF RECOVERY PLAN}

\subsection{PDCA Cycle}

In reality, it is difficult to foresee the economic situation 10 years after a disaster when planning a recovery process under the situation where the social situation is changing drastically. Moreover, in the recovery process for a large-scale disaster, issues to be tackled are changing as time goes by. Starting from emergency response to search and rescue and then relief followed by full-fledged recovery, the focal point shifts from recovery in structural aspects to enrichment in nonstructural aspects.

To flexibly handle the change in issues due to the impact of socioeconomic situations, the progress of recovery or citizens' awareness, the Kobe city government decided to adopt the PDCA management principle when implementing the Kobe City Recovery Plan. The PDCA management cycle is one tool used to help implement projects smoothly. This cycle adopts the following concepts for project implementation and management: plan it; $\underline{\mathbf{d} o}$ it; $\underline{\text { check it; }}$ act upon the results; and repeat these 4 processes continuously.

Based on the PDCA cycle concept, Kobe monitored the progress of each recovery project and reviewed and revised the plan when required. In fiscal year 1999, the last year of the first half (5 years) of the recovery plan, the city conducted a Comprehensive Recovery Assessment. This was to assess what had been done in the recovery process to date by checking the progress of each project and examining effective measures for the next 5 years in the areas of daily-life recovery, safe and secure city development, housing and urban reconstruction, and economic/port recovery. By taking the proposals based on the results into consideration, Kobe formulated the "Kobe City Recovery Plan Promotion Program" where the recovery measures to be dealt with in the latter term of the recovery process were indicated.

In fiscal year 2003, one year before the final year of recovery plan implementation, a second comprehensive assessment of recovery based on civic life, urban activities, housing and community development, and safe and secure city was conducted to examine Kobe Now (the current situation in Kobe) which had been rebuilt through the recovery process. The results were presented to the mayor of Kobe.

On the basis of the results, in fiscal year 2005, after the recovery plan implementation period was over, "New Vision (mid-term plan)" was formulated (target year: 2010). This aims at finding solutions for issues raised in the recovery process and at being the guidelines for future Kobe development through utilizing the experiences and lessons learned from the earth quake and the recovery process. In this way, after recovery plan implementation, the remaining recovery issues continued to be tackled within the framework of the city government's general measures and policies.

\subsection{System and Organization for Management}

The Kobe city government set up the "Kobe City Recovery Promotion Council" in 1996 to examine comprehensive progress control, necessary measures, issues concerning implementation of the recovery 
Figure 1. Progress of the Kobe City Recovery Plan Implementation

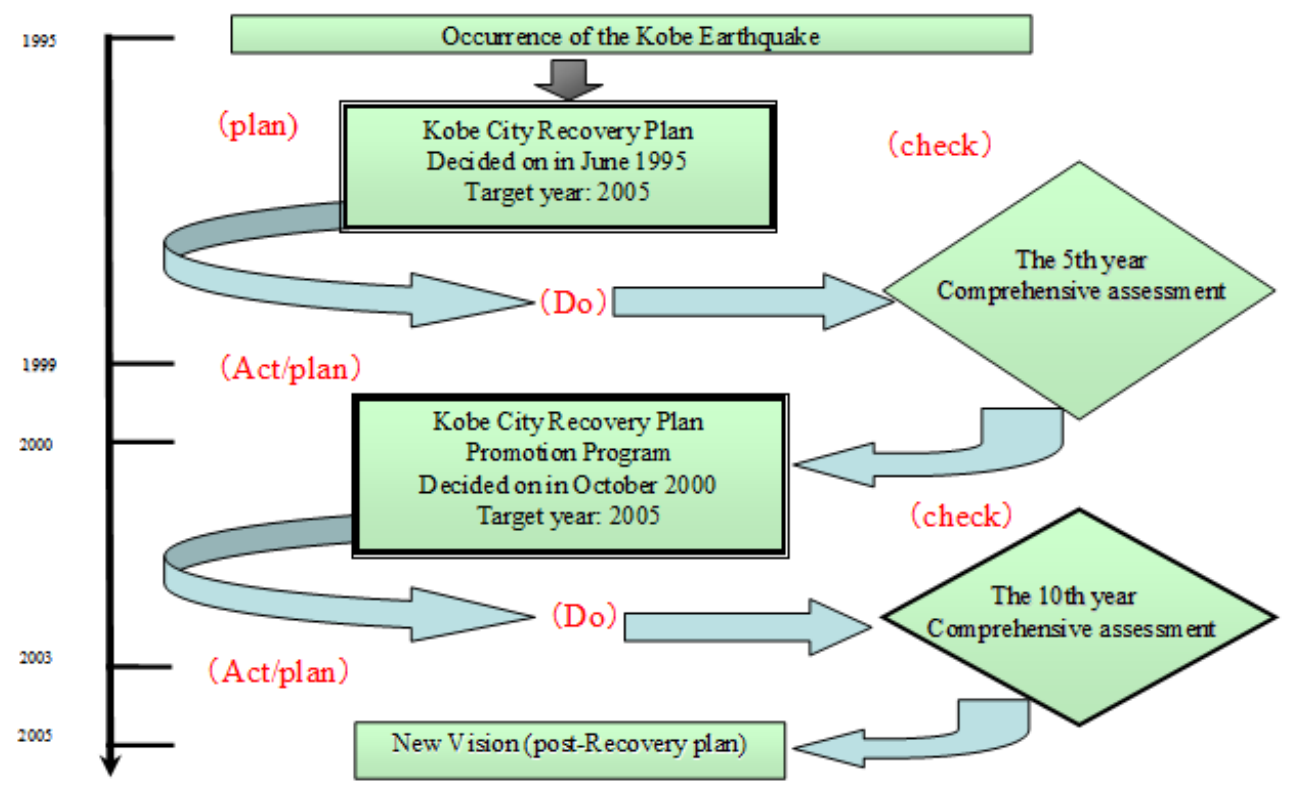

plan, and smooth and effective management. The objectives of this council were (1) to fully understand the progress of the recovery plan, (2) to clarify the remaining issues, (3) to examine potential measures to solve the issues, and (4) to submit proposals to the mayor of Kobe. For the council, members were selected based on the idea that opinions from a wide range of fields should be absorbed; as a result, 19 academic experts and 14 representatives divided among private organizations and citizens in light of promoting collaboration with citizens (33 in total) were selected. For 18 months after the council was set up, the members discussed a wide range of topics to prepare proposals for the mayor.

As time went by after the earthquake, many members voiced opinions that they should handle not only urgent issues for recovery but future-oriented issues in light of the coming of the $21^{\text {st }}$ century and long-term structural issues Kobe had long before the earthquake. To cope with this, the council was disbanded at their $6^{\text {th }}$ meeting. In its place, the Kobe City Recovery and Rejuvenation Promotion Council was established in June 1998 to handle long-term issues as well as recovery issues. Similar to the previous council, the city government chose the members from among academic experts, representatives of private organizations, and citizens.

As mentioned before, the Kobe City Recovery and Rejuvenation Promotion Council conducted comprehensive recovery assessments in fiscal year 1999 and 2003. The purpose of these assessments was to absorb opinions from various citizens to achieve a so-called grassroots assessment. The measures taken were workshops for Kobe citizens, questionnaires for 10,000 citizens, interviews with concerned people, and so on. Especially, the workshop methodology was found to be an effective measure to get opinions and proposals from all the participants. This methodology does not take a unilateral knowledge transmission style like a lecture but takes a meeting style featuring bilateral learning and creative thinking; this means that in the workshop participants actively engaged in discussions voluntarily to learn from each other and create something together through group synergy.

In the $2^{\text {nd }}$ comprehensive recovery assessment, the council solicited public comments to absorb citizens' opinions for their interim report and proposal to the mayor. By taking all opinions into consideration, the council finalized the proposal. 


\subsection{Evaluation Index for Recovery}

\subsubsection{Background}

In the comprehensive recovery assessment conducted by the Hyogo prefectural government, it was indicated that there were no numerical targets in their recovery plan, and strong desire to reach the targets was beginning to wane. There were other observations that it was difficult to monitor the recovery plan with policy evaluation methodology to assess the outcomes, because there were no numerical targets in the plan.

One reason clear numerical targets could not be set in the recovery plan is that, although it is rather easy to quantify the progress of structural development, there were no established evaluation methods for nonstructural measures, let alone benchmarks. Under the circumstances, the Kobe city government received the proposal from the Kobe City Recovery and Rejuvenation Council saying that Kobe should create an easy-to-understand index with citizens to share community development targets with them and to evaluate the achievements with them for implementing the "Kobe City Recovery Plan Promotion Program" (formulated in October 2000) through the collaboration between citizens and the government. This triggered the city government to adopt the administrative evaluation methodology to formulate the outcome index to measure the recovery targets and achievements. Kobe is probably the first administrative body to use the above index to monitor the progress of a recovery plan. The outcome index was named Citizen-Happiness Index.

Figure 2. Examples of the Citizen Happiness Index

Kobe City strives to be a city where volunteers, non-profit organizations (NPOs), and non-governmental organizations (NGOs) play an active role.

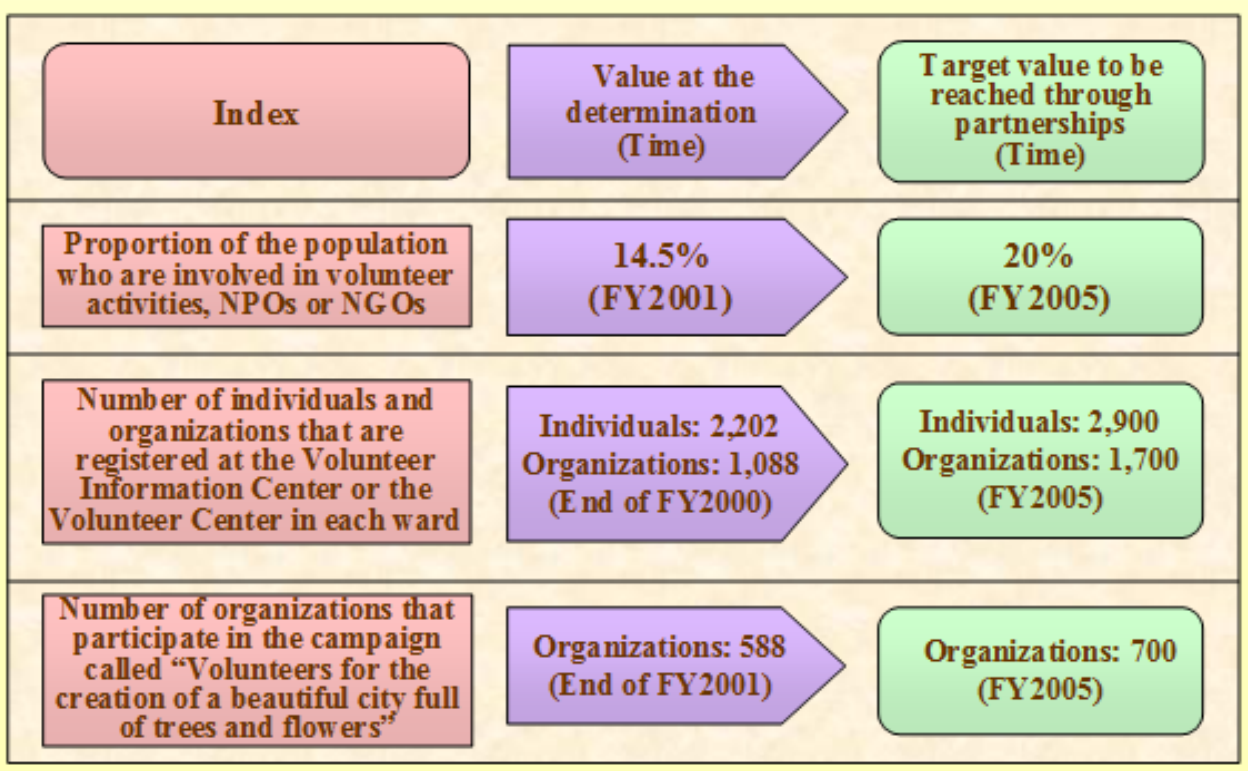

\subsubsection{Contents}

The Citizen-Happiness Index covers 16 prioritized measures called the 16-point Plan of Action under the "Kobe City Recovery Plan Promotion Program." The index consists of 45 individual indices with following characteristics. 
(1) Represented the targets to be reached through partnerships and the comprehensive results of the partnerships

(2) Could be represented numerically

(3) Could be compared with the index of other cities

(4) Represented changes in the daily lives of the citizens

(5) Reflected the citizens' awareness of the creation of communities as well as the needs of the citizens

(6) Utilized existing data, involved understanding information in daily business, and represented changes overtime

(7) Represented the characteristics of Kobe

Each index has "the value at the determination" when it was initially created and the goal value which is set to be reached by the cooperation among citizens, businesses and the government called "the target value to be reached through partnerships."

\subsubsection{Creation and Utilization of Citizen Happiness Index}

Citizens, stakeholders and the city government officers cooperated to select the individual indices. The selection processes were (a) index draft creation workshop by citizens (127 participants) and workshop with experts and academic experts (47 participants), (b) questionnaire survey for citizens to evaluate the index draft (637 replies), and then (c) citizens' workshop to narrow down the draft index to produce the draft bill (41 participants). In this way, the creation procedure itself is a form of cooperation: discussing matters to make decisions on an equal level between citizens and the government.

As for how to set the target value to be reached through partnerships, the following methods were adopted. If there were goal values for the above target values in the various Kobe plans or national plans, these values were adopted for the index as well; if not, the pre-earthquake values were adopted in case the values were related to the earthquake recovery, while values based on trend estimation from historic data development were adopted in some cases. In addition, the indices and the target values were reviewed and revised according to changes in social and economic conditions.

The progress of each individual index in the Citizen Happiness Index was uploaded onto the Kobe city government's website and updated as needed. The city government also prepared leaflets to distribute to the public to enable everyone to monitor the progress at any time.

\section{RESULTS OF COMPREHENSIVE RECOVERY ASSESSMENT}

As mentioned above, the Kobe City Recovery and Rejuvenation Promotion Council conducted comprehensive recovery assessment twice, in 1999 and 2003, with citizens' involvement. The $1^{\text {st }}$ assessment covered the problems in the first phase of recovery such as emergency response, relief measures, and reconstruction of urban infrastructures and port facilities. The $2^{\text {nd }}$ assessment covered Kobe Now, which had been rebuilt through the recovery process, while considering issues revealed by the $1^{\text {st }}$ assessment and new issues found as the recovery process continued.

The following sections introduce the major findings in each assessment session.

\subsection{Fifth Year Comprehensive Recovery Assessment}

\subsubsection{Overview of Recovery Situation}

The Kobe City Recovery and Rejuvenation Promotion Council overviewed the recovery conditions in Kobe 5 years after the earthquake. The council observed that urban infrastructures like port facilities and roads were restored to the original state in 2 to 3 years; infrastructural relief and recovery together 
with public housing constructions were completed; and all the victims were moved out from the temporary housing. Therefore, they concluded that structural bases in civic life were almost recovered within 5 year after the earthquake. On the other hand, the council pointed out that the remaining issues for the latter half of the recovery plan should be (1) citizens' life recovery, (2) economic recovery, and (3) safe and secure housing and community development.

The citizens' efforts for the recovery at that time were highly evaluated, because even under the severe economic conditions and with their anxieties in life, each of the citizens had a strong spirit focused on complete recovery on their own and made the utmost effort to do so, starting from calm attitudes and mutual help right after the earthquake through the early resuming of their businesses to their community development activities.

\subsubsection{Seven Critical Elements of Life Recovery}

Life recovery has a very large scope and is ambiguous. Therefore, the assessment of life recovery as one of the recovery projects started with clarifying the definition. Twelve workshops were conducted in Kobe to find out the following: (1) what life recovery means to earthquake victims; and, (2) what are the factors that citizens feel are helpful to the promotion of life recovery? In the workshops, a total of 269 victims and supporters participated and filled out 1,623 opinion cards. After sorting and categorizing these cards, it was clarified that a real sense of life recovery consists of 7 elements.

The following are the 7 elements in descending order based on the number of opinions submitted: (a) housing, (b) social ties, (c) community rebuilding, (d) physical and mental health, (e) preparedness, (f) economy, livelihood, and economic and financial situations, and (g) relationship to government.

In terms of housing, many homes were lost in the earthquake, and victims indicated the importance of efforts to provide housing, a daily necessity for life recovery.

All of the city's residents identified social ties as an important component in life recovery. When a disaster strikes, existing personal relationships are dissolved, and people are forced to create new personal relationships from scratch. This change in personal relationships is a major source of stress. Victims were reminded of the importance of social ties as they continued to face unfamiliar living situations.

Although the public infrastructure was restored within about two to three years after the earthquake, the overall recovery of communities seemed to still be a work in progress.

Physical and mental health are important preconditions for moving forward in life, and even five years after the earthquake, victims were still feeling a heavy toll on their mental health.

Those who lived through the earthquake developed an interest in earthquake preparedness as a result of their desire to avoid the recurrence of such a horrible experience.

In the fifth year after the earthquake, the prolonged stagnation of economic recovery and the wave of economic recession nationwide put additional pressure on victims who were already experiencing financial hardship as a result of the earthquake.

As for citizens' relationship to government, services often failed to meet the victims' expectations. This forced them to learn how to interact with their government.

\subsubsection{Self-Governance and Community Solidarity}

Out of the 7 critical elements of life recovery, 2 elements, housing and social ties, covered more than $50 \%$. Especially notable was the fact that the percentage related to social ties stuck out in comparison 
with the other elements.

Focusing on this fact, academic experts and experts in administration verified the cause and effect relationships and other factors in terms of social ties. As a result, the opinions of creating New Kobe through these cause and effect relationships were divided into 3 types: self-sustainable individuals, mutual help (coexistence/ solidarity), and establishment of attitude in daily social ties.

An individual takes actions by him/herself first. This means you do first and don't wait for somebody do something for you. Another aspect is the sense of a main player in community development. Self-sustainability often starts with self help.

Even though self-governance and self-sustainability is important, a single individual is has limited capability. To compensate for the limited capability of each individual and enhance mutual benefits of all individuals, coexistence and solidarity are the answers. What is important to recognize is that there are many people who have lost their assets in various ways and have difficulties making end meet in case of earthquake disasters.

However, mutual help has its limits, and it does not mean an individual can get any kind of help. Regardless of the situation, individuals should not feel that they are special and that others should do everything for them.

In the $5^{\text {th }}$ year comprehensive assessment, the key social ties for individual life recovery were integrated into two values and norms: self-governance and community solidarity.

Figure 3. Stories told in the 1999 Grassroots Workshop on Social Ties

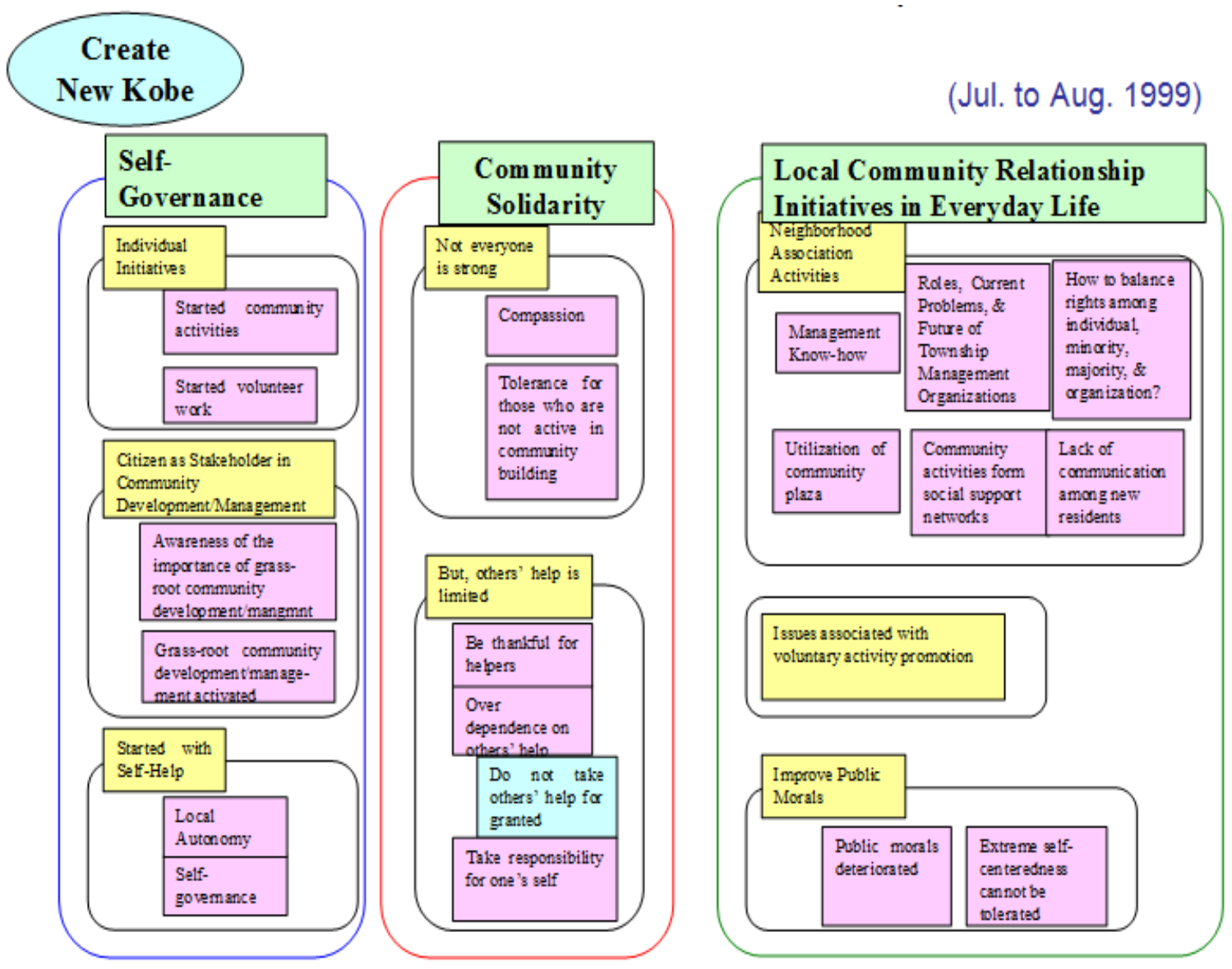


This self-governance and community solidarity was shown in a multidisciplinary way beyond the field of life recovery. Specifically speaking, community development promotion with self-governance and community solidarity was shown in the field of safe and secure city, housing and community development with self-governance and community solidarity in the field of housing and urban reconstruction, and self-governing recovery and community economy in economic and port recovery.

\subsection{Tenth Year Comprehensive Recovery Assessment}

In year 2003, the year before the final year of the plan, the Council conducted another Comprehensive Recovery Assessment to examine "Kobe Today," which means the state of the city as it had been rebuilt through recovery efforts taken up to that point.

\subsubsection{Comprehensive Assessment of Kobe Now, Remaining Issues, and New Challenges}

The city government examined to what extent Kobe Now and the earthquake experience were correlated. This was based on the results of the 10,000 questionnaires, economic-related data, etc. Through the examination, it was found that the correlation between Kobe Now and the earthquake was gradually waning under the prolonged recession and socioeconomic changes in the post-earthquake period.

Kobe Now (from the 2003 Comprehensive Recovery Assessment)

(1) Measures should be continuously taken to tackle earthquake-related issues.

(2) At the point when 8 years had passed since the earthquake, the national and structural issues had bigger effects than the earthquake itself.

(3) Some achievements from new efforts and projects in recovery were observed.

(4) New challenges emerged as time passed following the earthquake.

In the comprehensive recovery assessment, the direction of these efforts and projects was grouped by administrative field; among them the following were raised as major remaining issues.

(1) As for civic life, set up a permanent local friendly visitation program and take care of mental health issues.

(2) As for urban activities, continue the disaster recovery loan system and extend the Kobe Enterprise Zone Ordinance.

(3) As for housing and community development, finalize the urban development projects for reconstruction in earthquake stricken areas.

(4) As for a safe and secure city, increase seismic-resistant capacities for public facilities and housing structures.

\subsubsection{Lessons Learned from the Earthquake and the Recovery Process}

The earthquake not only caused severe damage in Kobe but also had great impact on people's sense of value, their way of life, and their attitude. It is important to confirm what was learned from the earthquake and the recovery process to be utilized for community development in light of considering the future direction of Kobe.

In the comprehensive recovery assessment, the lessons were divided into two categories: those lessons learned from the earthquake and those lessons learned from the recovery process. These lessons were reconfirmed as lessons looking towards the $10^{\text {th }}$ anniversary of the earthquake. 


\subsubsection{Lessons Learned from the Earthquake - Disaster Management Includes a Disaster Reduction Concept}

According to the Kobe City Recovery and Rejuvenation Promotion Council, all the lessons learned from the earthquake can be integrated into one phrase: the concept of disaster reduction should be included in disaster management.

In the earthquake, many urban infrastructures like housing and port facilities were destroyed, and it was found that those structures that were supposed to protect human lives or their assets were not perfectly safe or secure. From that fact, the lessons have shown that consideration of disaster management should be taken on the assumption that a disaster will occur. Thus, they said it was important that the concept of disaster reduction, protecting what should be protected such as life while minimizing damage, should be included in future disaster countermeasures.

Based on the above idea, enhancement of the capacity of safe and secure city development while utilizing the lessons learned from disasters through the total disaster management process, starting from preventive measures such as damage prevention and damage mitigation to the post-disaster countermeasures like emergency response and relief and recovery is required.

Specifically, the following 3 lessons were indicated.

(1) The earthquake reminded people of the severity of nature. Natural disasters will definitely occur in the future.

(2) Local community protects people's lives. Things should start from the place closest to the people.

(3) Actions people do not take in their daily lives cannot be undertaken in a disaster situation. Community development activities should be continuously ongoing in normal times.

When the Hanshin Earthquake hit, citizens' houses became lethal weapons, and many victims were crushed to death. In this context, it was important for individuals or households to increase seismic-resistance capacity and safety of their own homes, which are closest to them. At the same time, the importance of local communities and regular community development activities was recognized because many of the victims trapped under the debris of destroyed houses were rescued by their neighbors.

\subsubsection{Lessons Learned from the Recovery Process - from Self-Governance and Community Solidarity}

Following the earthquake, citizens recognized the importance of human-to-human ties, and this was recognized again during the recovery process. Each individual is self-sustainable by one's own responsibility, and one's presence should be positioned as a local community member; this recognition was enhanced during the recovery process. However, each individual's capability has its limit, and each individual needs to give help and consideration to others. This also creates an opportunity to generate human-to-human solidarity.

In the recovery process, unique individuals got together, and these social ties generated a new type of uniqueness. In this way, it was revealed that human-to-human solidarity generates self-governance.

Thus, self-governance and community solidarity are not unilateral factors but are enhanced by each other due to synergistic effects. As the lesson learned from the recovery process and that should be utilized in the future, that should be creation of a civic society where self-sustainable citizens are unified through solidarity.

Specifically, the following 5 lessons were emphasized.

(1) The meaning of recovery changes with the passage of time. 
(2) Recovery should be tackled flexibly through interrelated recovery fields.

(3) Community development is accomplished or enhanced by individual self-governing activities.

(4) Community development can be advanced by daily collaboration and individual participation.

(5) Recovery means moving towards a new system.

During the recovery process, while the issues were changing with time, citizens, businesses, and the city government provided their own wisdom to learn from each other to try to find solutions for the challenges they still faced. After the earthquake, things started from scratch. Under those circumstances, the city government firmly believes that Kobe proposed and created various new systems. In terms of administrative policies, the best examples are community-friendly visit programs and the Kobe enterprise zone. In addition, from the community side, defrayers' self-governance and other examples have been cited. Regarding the creation of the future Kobe, it is essential to utilize the lessons learned: the importance of proposing and creating new systems and attitudes to implement them.

\subsubsection{Basic Attitude towards Creation of the Future Kobe by Utilizing Lessons - Collaborative Community Development}

In Kobe, since the earthquake changed people's sense of value and way of life, the attitude of self-governance and community solidarity was enhanced, which led to new efforts and actions in the recovery process. The point is that these efforts and actions have been advanced by people's power and community's power. It is considered that collaborative and participatory community development has contributed a lot to this achievement.

Comprehensive recovery assessment shows why collaborative community development has been advanced in Kobe. According to the assessment, it was notable that not only individual power (human capital) but also the existence of social organizations (so-called social capital), whose features are the ability to enhance collaboration and networking, produced the driving force for advancement. The assessment also pointed out the following important issue for the future: collaborative community development made great achievements to handle individual issues during the recovery period; in light of moving on to the second stage, in order to implement this idea in a sustainable and comprehensive manner, social capital should be nurtured to eventually create a horizontal and highly-open network globally as well as locally.

\section{CONCLUSION}

As mentioned above, the following is the main feature of management of the Kobe City Recovery Plan: ever-changing issues were observed calmly, and the PDCA cycle was then adopted to control the progress by collaboration with citizens in order to cope with issues flexibly. This shows that citizens, businesses, and the city government got together to share wisdom and learn from each other how to implement the plan into the recovery process where the issues and challenges were changing day by day after the earthquake.

For the assessment of recovery, the city government adopted administrative evaluation methodology to create the Citizen-Happiness Index as outcome index. In the process of creating the index, even from the examination phase for each index, the city government solicited citizens' opinions and proposals; as a result, citizens and the city government could create the index through partnerships. These activities themselves have led to nurturing the citizens' awareness towards their own recovery and the progress of further efforts and activities; therefore, this seems to be one of the opportunities for victims and the government to work together to reach common goals.

The proposals from the $5^{\text {th }}$ and $10^{\text {th }}$ year comprehensive recovery assessments show that the following are important to proceed with recovery: self-governance and community solidarity, collaborative community development, and social capital. Based on this, Kobe formulated the New Vision (mid-term 
plan) in 2005. In the plan, Kobe aims at proceeding with collaboration and participation among private, academic, industrial, and administrative sectors to become a new city model ahead of the times. In this way, it is necessary to pass on the concepts of self-governance and community solidarity, collaboration and participation, and social capital to the next generation and forwards, since their importance was made clear during the recovery process.

\section{REFERENCES}

Kobe City, Kobe City Recovery Plan, 1995.

Kobe City Research Committee on Disaster Recovery, Kobe City's Review for Life Recovery, Kobe City, 2000.

Kobe City Recovery and Rejuvenation Promotion Council, Kobe City's Comprehensive Assessment for Recovery, Kobe City, 2003.

Kobe City, Comprehensive Strategy for Recovery from the Great Hanshin-Awaji Earthquake, 2010. 